1 Universidade Federal do Rio Grande do Sul (UFRGS), Programa de Pós-Graduação em Saúde Coletiva - Porto Alegre (RS), Brazil.

Orcid: https://orcid org/0000-0002-85756733

toneleo.90@hotmail.com

2 Universidade Federal do Rio Grande do Sul (UFRGS), Programa de Pós-Graduação em Saúde Coletiva - Porto Alegre (RS), Brazil.

Orcid: https://orcid. org/0000-0003-0110-

5739

daniel.canavese@gmail.com

3 Universidade Federal do Rio Grande do Sul (UFRGS), Programa de Pós-Graduação em Saúde Coletiva - Porto Alegre

(RS), Brazil.

Orcid: https://orcid. org/0000-0002-7153-

8882

bueno.ax@gmail.com

4 Universidade Federal do Rio Grande do Sul (UFRGS), Programa de Pós-Graduação em Saúde Coletiva - Porto Alegre

(RS), Brazil.

Orcid: https://orcid.

org/0000-0002-9408-

1504

ferlaalcindo@gmail.com

\section{Body, movement and health: connections from the point of view of complexity} Corpo, movimento e saúde: conexões sob a ótica da complexidade

Leonardo Tonelli1, Daniel Canavese ${ }^{\mathbf{2}}$, Alessandra Xavier Bueno ${ }^{\mathbf{3}}$, Alcindo Antônio Ferla4

DOI: $10.1590 / 0103-110420185419$

\begin{abstract}
Understanding the relationship between body, health, and movement beyond biological determinism and the current biomedical paradigm should consider other emerging interpretations that consider the multiplicity of the innumerable dimensions of which the triad can be composed as well as the different relationships that could exist between them. The paradigm of complexity is presented in this essay with the purpose of supporting other interpretations of physical activity that are less simplifying, linear and causal and that can incorporate openness, incompleteness, uncertainty and transdisciplinarity. The theory of complexity represents a stimulating and potent contribution to the dynamic study of the health-disease process and the physical activity in this panorama.
\end{abstract}

KEYWORDS Health. Human body. Exercise.

RESUMO Compreender a relação entre corpo, saúde e movimento além do determinismo biológico e do paradigma biomédico vigente consistiria em considerar outras interpretações emergentes e que consideram a multiplicidade das inúmeras dimensões das quais a tríade pode ser composta, além das diferentes relações que poderiam existir entre si. O paradigma da complexidade é apresentado neste ensaio com o propósito de amparar outras interpretações da atividade física que sejam menos simplificadoras, lineares e causais e que possam incorporar a abertura, a incompletude, a incerteza e a transdiscipliniridade. A teoria da complexidade representa uma estimulante $e$ potente contribuição para o estudo dinâmico do processo saúde-doença e a questão da atividade física nesse panorama.

PALAVRAS-CHAVE Saúde. Corpo humano. Exercício. 


\section{Background}

The body, movement and health: a triad of concepts that in addition to being interconnected and correlated, are open to various interpretations in relation to the paradigms and theoretical frameworks used to try to understand them. There is a universe of knowledge, discourses, and practices about movement and its relationship with health, each of which can be imagined as a fiber that is part of a larger fabric. This text aims to explore two different perspectives of these concepts: scientific thinking, which through its cartesian roots is capable of describing the specific characteristics of each fiber, and the paradigm of complexity, which shows us how the sum of these fibers can be larger than the fabric itself. Physical activity is the term commonly used to describe the body in movement and its contributions to health. It can be defined as any bodily movement produced by the skeletal muscles that results in energy expenditure above the base level ${ }^{\mathbf{1}, \mathbf{2}}$, and is internationally recognized as important to health due to its acute and chronic effects on cardiorespiratory and musculoskeletal capacity, its psychological benefits, and its preventive potential in relation to the onset and control of certain illnesses, especially chronic noncommunicable diseases ${ }^{3}$.

If on the one hand there is a consensus on physical activity's potential for promoting and maintaining health, the causal link between physical activity and these benefits can often seem controversial or contradictory. In addition, it must be noted that the relation between the body in movement and health explores social determinants and dimensions beyond the physiological effects on the organism, and thus ends up highlighting the limitations of any bio deterministic and reductionist understanding. There is a lot of scientific research studying the effects of regular physical activity on prevention and promotion of health. Such studies, predominantly aimed at developing recommendations and guidelines $s^{4,5}$, are largely focused on the biological, physiological and biomechanical aspects of this phenomenon. Because of this specific approach, they are not able to account for the social, cultural and political dimensions that affect individual and community health, that are related to the movement of people and their practices, and the senses and meanings associated with them.

The concept of complexity used in this study refers to the search for a 'new paradigm' that aims to go beyond simplifying, disjunctive, and reductive thoughts that 'separate and isolate', to embrace a complex interpretation of physical activity as a phenomenon that 'distinguishes and unites'. As stated by Edgar Morin, one of the theorists behind this paradigm, the term complexity, far from being synonymous with complicatedness, is a problem word and not a solution word 6 .

The theory of complexity dealing with concepts like fuzziness, emergency and not-linearity, represents a stimulating and innovative contribution to study the complex dynamics that regulate the health-disease process and the health systems, in social science in health approach ${ }^{7}$.

Classical science has produced a fragmentation of the phenomena studied through the super-specialization and hierarchization of knowledge, which leaves the different disciplines increasingly incapable of communicating between them and distancing them from everything that can not be measured, reproduced or controlled ${ }^{8}$.

Throughout the twentieth century, a series of scientific discoveries and advances created a gap in the western scientific paradigm, revealing the need for a complex, open, transdisciplinary and multicultural approach ${ }^{8}$. Complexity, until now confined to the periphery of what is considered scientific, is becoming more of a central issue. Studies on chaos and complexity are becoming increasingly common in other scientific fields (such as biology, cybernetics, information theory, chemistry, economics, psychology, and sociology), leading to a progressive and irreversible crisis of reason, just as conceived by classical science.

According to Morin', the challenge of interpreting reality through complexity arises 
from the simple approach's failure to tackle increasingly multidisciplinary, cross-sectional, multidimensional, transnational and global problems such as health, for example, by organizing knowledge into separate, fragmented, compartmentalized disciplines. The so-called paradigm of complexity does not deny that simplification is needed for the scientific world to understand the objects that surround us, nor does it try to eliminate it. Rather, it aims to incorporate simplifying paradigms into a comprehensive vision, rejecting reductionism and holism, based on the awareness that any interpretation of reality that does not become damaging, reductive, or one-dimensional must deal with the principles of incompleteness and uncertainty ${ }^{6}$ that characterize all phenomena.

The sciences of complexity tell us that it is a mistake to concentrate too much heavily on one or few factors if you want understanding the health models and trends of a certain population. It also suggests, through the concept of emergency, that we must look at whole systems rather than subdivide them into components, as is often the case when research ${ }^{10}$.

The decision to use the term physical activity in this study, aware of its bio-reductionist connotation and in order to (re)approach it in the light of the paradigm of complexity, was a political choice, a provocation that aims to rescue the terminology and ideals that it carries. Despite its definition being merely mechanistic, physical activity is universally used and recognized (and not only in the academic field) to identify systematized bodily movement in all its forms, and it is associated with senses and meanings that relate to living and caring for the body and to individual and collective well-being"11.

The relationship between the body, movement and health cannot be restricted to a linear and causal logic in which the body becomes the object and not the subject of its own health, belonging to a world of relationships and interactions with other subject bodies and the environment.

This assay aims to present an initial reflection based on complexity theory about body, movement and health and the limitations about this triad in the perspective of the biomedical model.

\section{Methodological strategy}

The present essay explores the methodological proposal of a science still under construction $^{12,13}$. In this sense, it is a partial and open review of the literature. The productions about the main subjects were selected by the authors to support the main arguments desired here. Therefore it incorporates uncertainty and it is not the target to undermine an issue and to close its perspective.

The difficulty of 'having to' adapt your own research in predetermined paths, based on the positivist model of classical science, exists also beyond the debate on the scientific legitimation of qualitative methodologies. It is not only about an attempt to legitimize the studies on the subjects, alives and uniques, inside the rigid scientific objectivity, made of statistical and mathematical methods designed to eliminate this subjectivity. This is about the possibility to build a path that can meet the formal requirements and scientific applications that an academic work requires and, at the same time, to venture out in searching a complex paradigm that is able to operate, not in the logic of dichotomies, which distinguishes and separates, but in the field of inter-relationships and interconnections between natural and cultural, subjective and objective, certain and uncertain, complete and incomplete.

According to Minayo ${ }^{\mathbf{1 4}}$, science has traditionally found its legitimacy in quantification, measurement and in production of data, with the claiming to be the driving force and criterion for the construction of the truth. However, even qualitative methodologies used by social scientists to study relations, history, representations, perceptions and interpretations of the subjects, in the scientific field, are 
deeply marked by the reproduction of a classic positivist model, which tends to generalize and regulate this phenomenon.

How to contemplate the 'unscientific' into the science?

The method is the path to take to get to a certain place, to answer the questions that have made you start walking. With the reason as a guide and doubt as a compass, scientific thought has always tried to create truths based objectification and disjunction of phenomena, fragmenting the whole into parts to be measured and analyzed. The scientific methodology seeks to build a one-dimensional vision, hierarchical and specialist, that enhances the regulations and standards.

The prospect of the complexity which this project works with, requires a strategic approach to the problem of the methodology.

The program it is the a priori determination of a sequence of actions having in view a target. [...] The strategy is established in view of a target as the program, it foreshadows action scenarios and chooses one, based on what he knows about that environment uncertain. Seeking tirelessly to bring together the information gathered with the fortuitous encountered on the way?.

The strategy will change depending on the information, situations and circumstances that meets along its journey. Once established the object of study, the actions that make up the methodological strategy will be at the service of this object and the questions that will arise during path, and not the opposite.

The purpose of investigating the relationship between body, health and movement in the light of the complexity paradigm, requires a certain openness to employ qualitative techniques and research tools, when you want to go exploring aspects relating to the history, the socio-political context and the meanings of this articulation, both in its specificity, as in its entirety. But always having in mind that quantity and quality are inseparable and interdependent.

\section{Main arguments}

\section{The body-organism and the medical- ization of physical activity}

Regarding care for the body, and more specifically in relation to physical activity as a means of building a healthy body, there is a culture ingrained in society that focuses on the notions of risk and lifestyle. When health is understood as a condition that is directly affected by physical exercise through a doseresponse correlation, a lack of movement becomes synonymous with illness, making the individual culpable for their own health and normalizing the notion of illness as a personal responsibility. Mira ${ }^{15}$ explains that although there are a large number of studies that would prove this cause-effect relationship between physical activity and health conditions, these studies make some problematic assumptions. Epidemiological studies that contribute to the construction of this causal link exclude other factors from analysis that, in addition to physical exercise, provoke physiological responses and adaptations by attributing the resulting effects exclusively to the activity. Assuming, therefore, that all these effects are considered healthy, such studies are based on a concept of health restricted to the organism, legitimizing the idea that the health of an individual or of a population can be determined by evaluating quantifiable physiological parameters.

This view has its roots in the cartesian school of thought and in the separation of the body-object-organism from the mind-subject-reason that distinguished the modernity and history of Western scientific thinking, the foundation of which is attributed to the philosopher René Descartes. However, as highlighted by Mendonça and Camargo ${ }^{16}$, Descartes cannot be considered properly 'cartesian' in that this term is related to the concepts of rationalism, determinism, mechanism and reductionism that characterize classical science. The french philosopher, aware 
of the difference between the living body and the body designed by reason, in addressing the platonic-christian dualism of the soul and body, void of its religious and mythological components, wanted to build a world of objects, the res extensa. In this world, he placed the body and the bodily experiences through which it interacts with other bodyobjects. Freed of any bodily influence, with its unpredictable and uncontrollable feelings and instincts that prevent achievement of the true knowledge of things, the soul may well inhabit the res cogitans, where pure intellect and mathematical reason constitute subjectivity related to the world ${ }^{\mathbf{1 7}}$.

With the development of rational scientific thinking, the body becomes an organism, the sum of the parts, an object among objects, insignificant and superfluous to understanding reality. Western scientific thinking takes the position that the truth can only be achieved through the functions of rationality and doubt. Empirical knowledge regarding discovery of the 'real world' through the body has lost its legitimacy to make room for cogito ergo sum ${ }^{\mathbf{1 8}}$ - I think therefore I am. Beyond the deductive cartesian method and through positivist elimination of the subject, modernity saw science establish the mind-body dichotomy, in which biomedical reductionism and its focus on illness is anchored.

The body that medicine first teaches about in the world of science is a corpse, a dead body, studied through its organs, bones, muscles, and nerves. To understand its functions through clear and distinct laws, medicine had to reduce it to an organism, comparing it to a machine made up of measurable and classifiable components and functions that can be controlled, manipulated, fragmented and governed like any other object.

But the dissected, emptied, decaying corpse is not the body, it is a model that only a knowledge measured in terms of death can understand as the true reality of the body [...] anatomy and physiology are condemned to not understanding anything about the body, because it is approached simply as a particular mode of death ${ }^{\mathbf{1 9}}$.

This reduction led to medical practices focusing on and developing from the concept of illness as a morphological and functional state of an organism, a deviation from the anatomical and physiological 'normality' of the perfect machine, becoming abnormal, sick. In the same way that illness becomes understood as 'abnormal', the absence of illness becomes synonymous with health. There is no space for suffering, pain, pleasure and happiness in this vision of health and illness, which is limited solely to the organism and determined from physiological parameters, scientific evidence, and epidemiological data.

When translated to health, the statistical concept of normality has intrinsic characteristics regarding what is most frequent and the imposition of a social value that makes such 'normality' acceptable in a given society. In 'The Normal and the Pathological', George Canguilhem ${ }^{20}$ tries to show that it is not possible to reduce the concept of health or the body to a purely biological concept. A body that lives with an illness, which suffers from it, is not a body-machine whose interactions with the environment can be calculated and reproduced. It is a 'subjective body', whose illness, far from being a transition from normal to abnormal, is the body's attempt to react to the disturbances of the environment, a new dimension of life.

The inability to consider aspects beyond the biological dimension of the health-illness process, as well as the need to deal with the complex problems of an increasingly globalized world, contributed to the crisis experienced by the biomedical paradigm and the beginning of a slow process of extending the concept of health, which is still ongoing.

The Lalonde Report, proposed in 1974 by the Canadian Health Ministry, represented a key point in the process of extending the concept of health and overcoming the 'state 
of complete well-being' model proposed by the World Health Organization (WHO) in 1946, which placed health in a static and unattainable position, incapable of forming a dialogue with the complexity of the reality, despite accounting for a multifactorial approach that includes other dimensions beyond the physical (social and mental) 21,22. With the International Conference on Primary Health Care, held in the city of Alma Ata in 1978 and the International Conference on Health Promotion held in Ottawa ${ }^{24}$, both organized by the WHO, international movements seeking to change the health paradigm began to emphasize aspects such as integrity, social equity, community participation, integration of health policies with other public policies, lifestyle, and health risks. However, despite intending to overcome the inequities and the preventative approach, aimed at reducing the risk of developing certain illnesses, the health promotion policies resulted in a number of interventions focused on changing and conditioning individual behaviors and habits by imposing healthy lifestyles, reproducing the health risk factors model. Within this context, the promotion of lifestyles ended up establishing a set of rules to be applied to bodies in order to distinguish the boundary between health and illness, what is healthy and what represents a risk, what is right and what is wrong.

In Michel Foucault's view ${ }^{25}$, the institution of mechanisms for disciplining, regulating and controlling people's lives and behavior results in the creation of medicalized discourses and practices based on the same reductionist and normalizing logic as that of the biomedical model. In addition to medical practice and other health professionals, this model also includes policies regarding life in all its forms, imposing a model that centralizes and normalizes illness, reducing it to a perspective of cause and effect, placing culpability and responsibility for the illness on the individual.

Society's control of individuals does not simply operate in the consciousness or via an ideology, but starts in the body, with the body. Capitalist society invested in the somatic, in the body, before anything else. The body is a biopolitical reality. Medicine is a biopolitical strategy 25 .

Discourses on what is known as 'active life', related to movement and physical activity for maintaining health, fall under this approach by associating the body-object of medical science with a society that values and treats the individual as absolute within the biological dimension, producing mechanisms that medicalize physical activity that become a means of control directed at the interests of production and the market.

Having a body therefore means responding to a series of aesthetic and behavioral characteristics dictated by a plurality of statistical and moral rules. These rules focus on the submission of bodies to health imperatives, which guide each person's existence through different means (magazines, television programs, advertisements, medical information, informative campaigns, public health policies, etc.), transforming everyday health practices such as weight management, blood pressure measurement, regular physical activity, and eating and sex habits, among other things.

Active life-promotion campaigns and programs to promote healthy lifestyles aimed at reducing risk factors and preventing nontransmissible chronic diseases are often legitimized by lower healthcare costs in terms of minimizing hospitalizations, physician visits and medications and potential increasing the quality of life ${ }^{26-28}$. But into a situation of world economic crisis where it is necessary to hold the individual responsible for taking care of his own health to rid the State, and the health system, of that weight, it may hide a number of biopolitical control devices. These strategies run the risk of focusing their own intervention on the glorification of active life and the demonization of sedentarism, with the purpose of influencing life choices and directing them to certain behaviors ${ }^{29}$. 
Bodily movement in its various expressions now plays a very important role in self-care and everyday health practices within the context of promoting lifestyles. In addition to representing an instrument for improving the body itself and constructing identities and forms that seek social recognition, bodily movement serves as a moral device for separating acceptable and displayable bodies (healthy, healed, athletic, sporty, active, etc.) from those that are undesirable and imperfect (ill, overweight, sedentary, lazy, etc.). The governing of bodies is sustained by discourses on active living thanks to the biomedical model, which constructs truths about the body as reduced to an organism, and powers the neoliberal health promotion market using security and risk logic, imposing rules and limits on which bodies constitute 'active' members of society.

One of the challenges of complex paradigms is the need for openness to a variety of interpretations, many of which are uncertain or even chaotic, involving diverse knowledge.

The essay explores aspects of this approach and its contributions to an interpretation of the relation between body, movement and health closer to an emerging paradigm of science that goes beyond the classical and cartesian perspective ${ }^{30-33}$.

\section{The body, health and movement be- yond simplifications: the contribution of complex thinking}

In his 'Letter to future generations', Ilya Prigogine, Nobel Prize winner for chemistry in 1977, described the emergency and need for the so-called 'new scientific spirit' that characterized the twentieth century, capable of overcoming the reductionist determinism and linear causality of the cartesian paradigm and embracing the concepts of chaos and unpredictability, which from the 1960s onward started becoming more prominent in the minds of scientists.

The entry of uncertainty onto the scientific landscape requires a reorganization of the latter into a new, post-cartesian paradigm that no longer intends to exhaust knowledge and impose itself as the only true key to interpreting reality, but instead assumes its intrinsic complexity, integrating elements such as incompleteness, contradiction, simultaneity, non-linearity, disorder, and emergency. Such elements, incompatible with the cartesian science of the so-called simplifying paradigm ${ }^{6}$, are more than necessary to approach and interact with the multidimensional problems of the physical and sociocultural phenomena of our time, such as health and its association with the body in movement, in our case.

According to Maria Conceição de Almeida ${ }^{34}$, moving on from the cartesian scientific model does not mean foregoing scientific rigor. On the contrary, she assumes its reformulation:

Faced with complex phenomena that is unequal, dynamic and largely unpredictable, rigor cannot be anything other than a way of identifying phenomena that is characterized by mutability and openness. From this perspective, the more dialogue with the various mutating dimensions of a phenomenon, the more rigorous the interpretation will be [...] We could say that rigor is more rigorous now because researchers face the challenge of having to more closely approach the unpredictable and partly indecipherable dynamics of the phenomena that they are studying ${ }^{34}$.

The construction of a complex scientific paradigm is related to the attempt to unite the two worlds separate by modernity, scientific rationalism and empiricism phenomenal, 'body object' and 'body subject', without one excluding the other. Only then would we be able to distinguish between them without separating them and unite them without causing confusion' ${ }^{6}$.

Recognizing the limitations and weaknesses of the biomedical model in relation to the discourses and practices that surround the movements, senses and meanings with which it is associated highlights the need 
to find a multidimensional and non-reductive way of thinking about physical activity in health. The aim, therefore, is not to deny the potential benefit of physical activity on people's lives, but to relocate it from the medicalized dose-response logic to a model that takes into account the determinants, inequality and diversity that both individuals and health systems have to deal with.

In this part we are going to exercise, with the help of some examples, some of the possible connections with the dialogic, organizational recursion and holographic principles ${ }^{6}$, as well as their contributions to complex thinking regarding the relationship between body in movement and health, are addressed below. The study of the complexity related to physical activity and health is an incipient field in continuous construction. Moreover, the paradigm of complexity for its intrinsic and constituent features works with open, unfinished, and contemporary concepts, so the examples that will be reported below should not (and can not) be considered as applications of these principles to reality. These are approximations that in different contexts try to explore non-simplifying approaches and integrate different types of causality.

The dialogic principle: having or being a body?

Order and disorder are two enemies: one suppresses the other, but at the same time, in certain cases they collaborate and produce organization and complexity. The dialogic principle allows us to maintain the duality within the unity. It connects two terms that are at the same time complementary and antagonistic ${ }^{\mathbf{3 6}}$.

Duality as presented by this principle is no longer synonymous with separation, rather it is a means to achieving unity and returning the body to its original ambivalence. It was Maurice Marleau-Ponty who, from the phenomenological perspective, described human beings as 'bodily beings', shifting the focus from the cartesian view of 'having a body' to the preeminently bodily and existential dimension of 'being a body' in the world 36 . From this perspective, the body unites the complexity of feeling, thinking, gesturing, and expressing itself to overcome the modern dichotomy of the body as an organism, an object of scientific reason, and a sociocultural product, which still tries to achieve bodily unity directly within the experience of interacting with the 'real world'. No longer an object of the mind, where it is stuck within itself, but the body as itself.

The biological, social, cultural and symbolic dimensions of the body coexist, but not in a dichotomous and incompatible way. On the contrary, they represent the simultaneity of the one and the multiple. The body is eminently biological, but at the same time it is social, cultural, political, and part of a universe of unique languages for each cultural reality, with its notion of senses and meanings in relation to movement and health. The scientific view of the body as an object is (was, and will be) essential to understanding the physical and biological phenomena of our organism, but a complex vision of health must aim to integrate this view into its diversity and multiplicity.

One of the most effective attempts to undermine the concept of the body as a natural and biologically determined object, to embrace the idea of an individual as a result of a complex mechanism of embodiment, has been exercised by Gender Studies which have developed since the 1990s and in particular from Queer Theory ${ }^{38}$. This perspective is engaged in the deconstruction of the sex/gender system, which means the whole of all those through which society tends to transform biological sexuality into practices and meanings, thus building up gender. The sex/gender system in this reading does not correspond to the dualism nature/culture, but goes beyond mere dichotomous opposition, trying to convert cultural factors into natural data ${ }^{39}$.

This type of study shows clearly how when we talk about the body, it is impossible to draw a line between what is natural and what is culturally determined, as the plans become blurred and become more and more fuzzy. 
Organizational recursion: does physical activity produce health, or does health encourage physical activity practice?

Organizational recursion is a process in which the products and effects are at the same time causes and producers of what they produce [...] We are simultaneously products and producers. The recursive principle is directly opposed to the linear idea of cause-effect, product-producer, structure-superstructure, stating that everything that is produced returns to what produced it in a self-constituting, selforganizing and self-producing cycle ${ }^{36}$.

Modern epidemiology operates based on the notion of risk, often articulated by mathematical models and the cause-effect relationship, which links individual behavior to health conditions with no consideration of life history or social context. The correlation between systematic, regular physical exercise and health benefits and prevention of illness, scientifically recognized by a large number of epidemiological studies, is based on a probabilistic causal link.

This perspective can be simplified to the extent that it addresses only part of the problem. It connects physical fitness, achieved through regular exercise, to a reduction of illness or increased life expectancy.

For Morin, complex causality is expressed retroactively and recursively and it is not only deterministic or probabilistic, but also a creator of the 'improbable'39. Such causality needs to be studied and expanded in order to explore the potential of the connection between physical activity and health in a way that is not simplified or biologically determined. Thus, returning to the previous question, physical activity can be considered both the producer and product of better health conditions, to the extent that it is determined both by the biological sphere and by a set of sociocultural senses and meanings with which it is associated.

Wiltshire, Fullagar, Stevinson ${ }^{40}$ in a study of the 'Parkrun' experience, claim that the senses of collective participation can somewhat lessen the effects of individual responsibility for health. They call attention to the various social issues that interfere, for example, in the process of an individual moving from inactive to physically active. The authors make a call for health promoters:

Consider how physical activity opportunities could recognise the value of collective contexts and understand how bodywork is performed and shaped through different social practices $[. .$.$] becoming active is a neces-$ sarily complex process that involved not only invoking an individual will to health through mobilising discourses of discipline, guilt and rationality, but also through making available subject positions that individuals may have previously been excluded from $\mathbf{4 0}^{\mathbf{0}}$.

This study, exploring the sociocultural context of embodied experiences of physical (in)activity and analyzing embodied experiences of parkrun, a free, community-based, $5 \mathrm{~km}$ running event in local parks, emphasizes the inability of the physical activity promotion interventions to effectively address complex problems in non-controlled conditions and to translate this interventions into real-world settings.

The holographic principle: when is physical activity a health practice?

Not only is the part in the whole, but the whole is in the part. The holographic principle is present in the biological world and in the sociological world [...] The idea, therefore, is that the hologram goes beyond both reductionism, which considers only the parts, and holism, which considers only the whole ${ }^{35}$.

The problem with complexity in relation to the link between physical activity and the health-illness process becomes more evident when discussing public health policies, and biological determinism is rejected in favor of an 'extended' concept of health. With respect to extending the concept of health, this study 
understands the process of complexifying the bio-reductionist and currently hegemonic view, which sees the health-illness process as limited solely to the organism itself, to consider it as an open system, capable of selforganizing itself, part of an ecosystem of physical, interpersonal, socioeconomic, market, and (bio)power relationships. Sabroza ${ }^{41}$ recognizes an articulated, complex system within the health-illness process, with different dimensions (biological, psychological, economic, social, cultural, individual, collective) that are arranged into different organizational levels (molecular, cellular, individual, social group, society, global). Depending on the position of the observer, such a process can thus be interpreted as cellular change, individual suffering, or a public health problem.

From this perspective, the concept of physical activity must be rethought in order to understand how and when it can be considered a health practice.

For Madel Luz $\mathbf{4 2}^{\mathbf{2}}$, when health starts to be considered as an absolute value, the society becomes a so-called 'health utopia'. In this sense, extending the concept could result in a holistic view that aims to escape from reductionism in order to incorporate a wide variety of everyday practices without distinctions, to the point that any activity (such as sport or recreational, aesthetic, or erotic activities) can be considered a health practice. The problem is that a complex view of health (as a whole, which is more than the sum of its parts) is confused with the medicalization of life dictated by the normalization of behavior and market interests, following a perfect ideal of permanent good health and well-being, based exclusively on the biological body. Defining health as a complex phenomenon means understanding health and illness in a nonexclusive way, as antagonistic and complementary at the same time. For Almeida Filho ${ }^{43}$, understanding the health-illness object means reaching a full and complete understanding of its multiplicity within unity.

The Academia da Saúde Program, was launched by the Brazilian Ministry of Health in 2011, with the main objective of contributing to the promotion of population health through the establishment of infrastructure, equipment and personnel qualified to guide practices physical activity and leisure and healthy lifestyles. Although the name 'academia' (gym) refers to ideas based on common sense about physical activity ${ }^{44}$ may be an example of how these approaches to a complex reading of the triad body, health, and movement are emerging in health promotion practices. By listing the axes of the activities that must be developed, the program refers to 'body practices and physical activities'45, which assumes that there are two theoretical references that contemplate different elements as already mentioned above. When one takes into account the culture and ways of producing encounters in the planning and execution of health actions (and is not different with physical activity), it is also putting in the agenda the relations of people with the body movement and how it is health or illness in different contexts. The 'body practices' change in form, meaning and function, according to the transformations and characteristics of the socio-historical contexts in which they are inserted ${ }^{46}$.

The methodological strategy, capable of explaining the complexity of health phenomena, is not limited to multiple views cohabiting or coexisting in a certain scientific field, but unity needs to be found in this vast, complex diversity of objects, outlooks and views ${ }^{\mathbf{4 3}}$.

Health and illness coexist as dynamic phenomena in people's lives and differ in their uniqueness and their ability to deal with the disturbances of their own realities.

Overcoming the reductionist biomedical model to (re)interpret the link between physical activity and the health-illness process within the complexity paradigm can help us to rethink the practices related to the body in movement within health systems, from a perspective not of healing, preventing, and 
controlling, but of producing methods of care that can consider the other dimensions that compose the life of each subject.

\section{Conclusions}

The main intention of this text was to highlight the links between the body, movement and a wide perspective of concept of health with the perspective of complexity. We demonstrated how the term physical activity, despite being linked to a bio-reductionist view of human movement, recalls a number of senses and meanings related to the social and cultural dimensions and health policies that are ignored and devalued by this approach. We attempted to explore the possible ways that the complexity paradigm can help to understand and overcome such weaknesses.

The body in movement, detached from the scientific reductionism of the biomedical model, presents other possibilities for healthcare. Not linked by a unidirectional, linear causality, but by a recursive causality that needs to be studied and extended. We did not attempt to deny the beneficial effects of regular physical exercise on the body, but when we talk about public health promotion policy in a broad sense, we must be aware that the bio-reductionist view of physical activity only shows us a small glimpse of the many possibilities that systematized bodily movement provides as a healthcare practice.

Simplification of physical activity in public health, when reduced to a mere strategy for lowering cholesterol levels and controlling blood pressure and body weight, in addition to a total disinterest in its relationships and interrelationships with the environment and between people, reflects its interpretation as a medicalized element. It also leads to a widespread understanding of physical activity as a medicine that can be administered, prescribed and 'taken' in a passive and guided manner, without taking into account the meanings, interests and requirements attributed to it.

As corporeal beings, the suffering caused by illness is experienced by and through the body, in the same way that it experiences happiness and pleasure. Physical activity is a producer of care in that it can account for the senses and meanings that people assign to this practice regarding their own health. The great challenge to understanding the body-movement-health triad beyond biological determinism lies in considering the multiplicity of the different dimensions of which it is composed, in addition to the relationship that these dimensions have with the organism and its illnesses. By adopting a view of health that does not intend to reduce and simplify, and is able to interact with the complexity of the living systems, it is possible to think of care practices involving physical activities that aim to promote health in a way that goes beyond the logic of imposed lifestyles, individual accountability and culpability, and normalization of the illness process.

In this paper, we have tried to show how these issues must be approached in the least simplifying and reductive way possible in order to appreciate the relationship between the body, movement, and health, abandoning the scientific illusion of an objective and complete universe to embrace the blurring of reality. Considering the body in its unity, using physical activity as a healthcare practice, it is impossible to determine it as purely biological or solely as a sociocultural product, because limiting its multiplicity and its duality within its unity damages its power in relation to the complexity of health.

\section{Contributors}

All authors contributed to the conception and planning, critical review of content and approval of the final version of the manuscript. 


\section{References}

1. Caspersen CJ, Powell KE, Christenson GM. Physical activity, exercise, and physical fitness: definitions and distinctions for health-related research. Public Health Rep. 1985 Mar-Apr; 100(2):126-131.

2. American College of Sports Medicine. ACSM's guidelines for exercise testing and prescription. Philadelphia: Lippincott Williams \& Wilkins; 2014.

3. Word Health Organization. Global Recommendations on Physical Activity for Health, WHO Library Cataloguing-in-Publication Data. Geneva: WHO; 2010.

4. Blair SN, LaMonte MJ, Nichaman MZ. The evolution of physical activity recommendations: how much is enough. Am J Clin Nutr. 2004 May; 79(5):913-920.

5. Haskell WL, Lee IM, Pate RR, et al. Physical activity and public health: updated recommendation for adults from the American College of Sports Medicine and the American Heart Association. Med Sci Sports Exerc. 2007 Aug; 39(8):1423:1434.

6. Morin E. Introdução ao pensamento complexo. Porto Alegre: Sulina; 2005.

7. Tenbensel T. Complexity in health and health care systems. Soc Sci Med. 2013; 93:181-184.

8. Almeida MD. Tecnociência e globalização. In: Almeida MD, Carvalho EA. Cultura e pensamento complexo. Porto Alegre: Sulina; 2012.

9. Morin E. A cabeça bem-feita: repensar a reforma, reformar o pensamento. Rio de Janeiro: Bertrand Brasil; 2014.

10. Eckersley R. Beyond inequality: Acknowledging the complexity of social determinants of health. Soc Sci Med. 2015 Dec; 147:121-125.

11. Carvalho YM. As práticas corporais e a atenção primária em saúde: avaliando os cuidados com o corpo nas unidades básicas do distrito Butantã em São Pau- lo [projeto de pesquisa]. São Paulo: Fapesp; 2007.

12. Feyerabend PK. Against method: Outline of an anarchist theory of knowledge. London: NLB; 1978.

13. Latour B. Science in Action. Cambridge: Harvard University; 1987.

14. Minayo MC. O desafio do conhecimento: pesquisa qualitativa em saúde. 10. ed. São Paulo: Hucitec; 2007.

15. Mira CM. Exercício físico e saúde: da crítica prudente. In: Bagrichevsky M, Palma A, Estevão A. A saúde em debate na educação física. Blumenau: Edibes; 2003. p. 33-51.

16. Mendonça AL, Camargo Júnior KR. Os acertos de Descartes: implicações para a ciência, biomedicina e saúde coletiva. Cad. Saúde Pública. 2016 May; 32(5):1-9.

17. Galimberti U. Il corpo. Milão: Feltrinelli; 1987.

18. Descartes R. Discurso do Método. São Paulo: Martins Fontes; 2001.

19. Galimberti U. Il corpo. Milão: Feltrinelli; 1987.

20. Canguilhem G. O normal e o patológico. Rio de Janeiro: Forense Universitária; 1995.

21. Caponi S. Georges Canguilhem and the epistemological status of the concept of health. Hist. cienc. saude-Manguinhos. 1997 Oct; 4(2):287-307.

22. Fundação Oswaldo Cruz. Escola Politécnica de Saúde Joaquim Venâncio. Dicionário da Educação Profissional em Saúde [internet]. Rio de Janeiro: EPSJV; c2009 [accessed in 2018 jan 5]. Avaiable in: http:// www.epsjv.fiocruz.br/dicionario/.

23. World Health Organization. Declaration of Alma-Ata: International Conference on Primary Health Care, Alma-Ata, USSR, 6-12 September 1978. [Geneva]: WHO; 1978. 
24. World Health Organization. The Ottawa charter for health promotion: first international conference on health promotion, Ottawa, 21 November 1986. [Geneva]: WHO; 1986.

25. Foucault M. Microfísica do poder. Rio de Janeiro: Edições Graal; 1984.

26. Andreyeva T, Sturm R. Physical activity and changes in health care costs in late middle age. J Phys Act Health. 2006 Feb; 3(supl.1):6-19.

27. Hagberg L. Cost-effectiveness of the promotion of physical activity in health care [tese]. Sweden: Umea University; 2007.

28. Pratt M, Macera CA, Wang G. Higher direct medical costs associated with physical inactivity. Phys Sportsmed. 2000 Oct; 28(10):63-70.

29. Fraga AB. Exercício da informação: governo dos corpos no mercado da vida ativa. Campinas: Autores Associados; 2006.

30. Capra FA. Teia da Vida. São Paulo: Cultrix; 2010.

31. Feyerabend PK. Adeus à razão. São Paulo: Unesp; 2010.

32. Santos BS. Um discurso sobre as Ciências. 7. ed. São Paulo: Cortez; 2010.

33. Rancière JO. Mestre ignorante. 3. ed. Belo Horizonte: Autêntica; 2015

34. Almeida MD. Complexidade, saberes científicos, saberes da tradição. São Paulo: Livraria da Física; 2010.

35. Morin E, Lisboa E. Introdução ao pensamento complexo. Porto Alegre: Sulina; 2005.

36. Maurice MP. Fenomenologia da percepção. São Paulo: Martins Fontes; 2006.

37. Bulter J. Gender trouble. London: Routledge; 1990.
38. Virgili E. Olimpiadi: l'imposizione di un sesso. [Local desconhecido]: Mimesis; 2012.

39. Morin E. O Método a natureza da natureza. 2. ed. Porto Alegre: Sulina; 2005.

40. Wiltshire GR, Fullagar S, Stevinson C. Exploring parkrun as a social context for collective health practices: running with and against the moral imperatives of health responsibilisation. Sociology of health \& illness. 2018 Jan; 40(1):3-17.

41. Sabroza PC. Concepções de Saúde e Doença. Rio de Janeiro: Fiocruz; 2001.

42. Luz MT. Novos saberes e práticas em saúde coletiva. São Paulo: Hucitec; 2003.

43. Almeida Filho NA. Saúde e o Paradigma da Complexidade. In: Ciclo de estudos sobre 'O Método' de Edgar Morin. São Leopoldo: UniSinos; 2004. p. 1-47.

44. Gomes LB, Bueno AX. A educação permanente no cotidiano do trabalho em saúde: reflexões iniciais sobre suas interfaces com o Programa Academia da Saúde. In: Gomes LB, Bezerra L. A educação permanente em saúde e as redes colaborativas: conexões para a produção de saberes e práticas. Porto Alegre: Rede UNIDA; 2016.

45. Brasil. Ministério da Saúde. Portaria GM No 2.681, de 7 de novembro de 2013. Redefine o Programa Academia da Saúde no âmbito do Sistema Único de Saúde (SUS). Diário Oficial da União. 7 Nov 2013.

46. González FJ. Práticas corporais e o sistema único de saúde: desafios para a intervenção profissional. Práticas corporais no campo da saúde: uma política em formação. In: Gomes IM, Fraga AB, de Carvalho YA. Práticas Corporais no Campo da Saúde: uma política em formação. Porto Alegre: Rede UNIDA; 2015.

\footnotetext{
Received on 22/08/2017

Approved on 21/05/2018

Conflict of interests: non-existent

Financial support: non-existent
} 